\title{
THE EFFECT OF NON-METALLIC INCLUSION SIZE AND ORIENTATION ON TENSILE PROPERTIES OF STAINLESS STEEL (SIMULATION AND EXPERIMENT)
}

\author{
Peyman Ahmadian*, Mahdi Taghizadeh \\ Metallic Material Research Center (MMRC), Malek Ashtar University of Technology, \\ Tehran, Iran
}

Received 29.01.2020

Accepted 13.04.2020

\begin{abstract}
In this study, the effect of non-metallic inclusions (NMIs) on tensile behavior of titanium stabilized Fe-20Cr-9Ni steel was investigated. The size of NMIs was decreased via the electro-slag remelting (ESR) process. JK-inclusion rating method revealed that the studied steel consisted of D-type (square-shaped) inclusions. According to energy dispersive spectroscopy, it was determined that the appeared inclusions in the matrix of the titanium stabilized Fe-20Cr-9Ni steel is predominantly titanium nitride (TiN). As a result of the ESR process, excellent improvement in the tensile properties of the studied steel was observed. Subsequently, the effect of inclusion size $(d=5,10,25,50 \mu \mathrm{m})$ and orientation $\left(\alpha=0,45^{\circ}\right)$ on stress concentration factor around the non-metallic inclusion and metallic matrix was simulated. The result of finite element analysis indicated that, for both square $\left(\alpha=0^{\circ}\right)$ and rhombus $\left(\alpha=45^{\circ}\right)$ shape inclusions, increasing inclusion size has resulted in high-stress concentration factor during plastic deformation. On the other hands, generated Mises stress field around the non-metallic inclusion presented that, for the same inclusion size, rhombus $\left(\alpha=45^{\circ}\right)$ shape inclusion is more susceptible to homogenous deformation in comparison with square $\left(\alpha=0^{\circ}\right)$ one.
\end{abstract}

Keywords: non-metallic inclusion; stainless steel; stress concentration factor; finite element analysis; electro-slag remelting.

\section{Introduction}

Stainless steels play an important role in all emerging technologies [1]. According to previous researches, it can be declared that the mechanical properties of steels depend on chemical composition [2], microstructure [3, 4] and crystallographic texture [5-7]. Non-metallic inclusions (NMIs) are another critical parameter that has a significant influence on the properties of engineering alloys. Generally, there are external and

*Corresponding author: Peyman Ahmadian,pahmadian7@gmail.com 
internal sources for the generation of NMIs which are nominated as exogenous and endogenous resources, respectively [8]. Non-metallic inclusions are classified as micro and macro inclusions according to their dimensions. Most of the inclusions are submicroscopic and their size is within a range of $0.1-100 \mu \mathrm{m}$ [9]. Many studies have been conducted on the role of NMIs on the mechanical properties of steels. The effect of $\mathrm{MnS}$ inclusion size on toughness properties of $32 \mathrm{CDV} 13$ steel was investigated by Arreola-Herrera et al. [10]. The result indicated that decreasing inclusion size is associated with higher fracture toughness and more planar isotropic behavior. Also, it was revealed that crack nucleation and propagation has occurred at a lower level of applied stress as a result of dendritic MnS inclusions in 42CrMo4 steel [11]. The size, distribution, volume fraction, morphology and chemical composition of non-metallic inclusions has been known as critical parameters for crack propagation and fatigue properties of steels [12-14]. In general, the presence of inclusions can cause surface defects and deteriorate the mechanical properties of steels. However, inclusions can introduce beneficial effects about the machinability of steels [15]. Despite impressive progress in steelmaking technology, the formation of NMIs is regarded as an exciting challenge for both steel producers and consumers. The formation of NMIs during the steelmaking process is inevitable. Hence, the term inclusion engineering has been introduced in steelmaking technology [16]. This branch of research deals with new and modern techniques for decreasing the size and volume fraction of NMIs in order to improve the properties of steel. The electro-slag remelting process is one of the modern and conventional techniques for improving steel cleanliness [17]. In previous studies, the effect of the electro-slag remelting process on microstructure, inclusion content and mechanical properties of bearing steel G20CrNi2Mo [18], H11 tool steel [19], 316 LC stainless steel [20] and STN 14109 steel [21] were investigated. Also, the number of inclusion has been significantly reduced in non-oriented electrical steel during the Aluminium deoxidation process [22]. In this research, the size of non-metallic inclusion is reduced and the ESR process achieves cleanliness stainless steel. Then, the effect of non-metallic inclusions size and content on tensile properties of the studied steel was evaluated. Subsequently, the value of stress concentration factor around the non-metallic inclusion and metallic inclusion was estimated using finite element analysis. The effect of inclusion size $(\mathrm{d}=5$, $10,25,50 \mu \mathrm{m})$ and its orientation $\left(\alpha=0,45^{\circ}\right)$ through tensile loading was simulated by Abaqus software. 


\section{Experiment}

The chemical composition of the studied stainless steel (Table 1) is analyzed using emission spectroscopy (metal analyzer M $5000 \mathrm{~S}$ ). It is in the permissible range of Fe20Cr-9Ni steel [23]. The titanium element was added to the steel for stabilization [24]. Therefore, the studied alloy can be certainly referred to as titanium-stabilized stainless steel. In addition to stabilization, titanium binds nitrogen as a titanium nitride (TiN) which will obviously be extracted by optical microscopy and SEM topography.

Table 1. The obtained result of emission spectroscopy analysis for the studied steel.

\begin{tabular}{lllllllllllll}
\hline Mo & $\mathrm{S}$ & $\mathrm{P}$ & $\mathrm{Mn}$ & $\mathrm{Si}$ & $\mathrm{Ti}$ & $\mathrm{Cr}$ & $\mathrm{Ni}$ & $\mathrm{N}$ & $\mathrm{C}$ & $\mathrm{Cu}$ & $\mathrm{Fe}$ \\
\hline 0.26 & 0.01 & 0.03 & 1.13 & 1.05 & 0.61 & 20.11 & 9.14 & 0.03 & 0.02 & 0.02 & bal. \\
\hline
\end{tabular}

The studied ingot has been melted three times by the ESR process in order to reduce the size of non-metallic inclusions and achieve a homogenous microstructure. ANF-6 slag with the composition of $70 \% \mathrm{Al}_{2} \mathrm{O}_{3}-26 \% \mathrm{CaF}_{2}-4 \% \mathrm{TiO}_{2}$ was selected via the ESR process. The current intensity and voltage of the ESR process were $1700 \mathrm{~A}$ and $20 \mathrm{~V}$, respectively. During the ESR process, its parameters were kept the same for each melt. In the following, the microstructure of the steel was obtained using the conventional metallographic method. Then, the influence of the electro-slag remelting process on the size and distribution of inclusions was examined using optical microscopy (OLYMPUS BX51) and scanning electron microscopy (VEGA3 TESCAN). The appeared inclusions in the studied steel were characterized according to the JK inclusion rating method (ASTM E45). The chemical composition of non-metallic inclusions was analyzed using an energy dispersive spectrometer (EDS). Tensile properties of the studied steel were carried out before and after the electro-slag remelting process according to ASTM E8. Subsequently, the stress concentration factor at the interface of the metallic matrix and non-metallic inclusion was simulated using finite element analysis. For this purpose, the effect of inclusion size $(d=5,10,25,50 \mu \mathrm{m})$ and its orientation $\left(\alpha=0,45^{\circ}\right)$ through tensile loading was simulated by Abaqus software.

\section{Simulation condition}

The effect of the inclusion size and its orientation through-loading direction on the value of stress concentration during plastic deformation was simulated by Abaqus software. The size of the matrix was assumed to be $200 \times 200 \mu \mathrm{m}$. One non-metallic inclusion was located at the center of the metallic matrix. The inclusion size was regarded to be $5,10,25$, and $50 \mu \mathrm{m}$. Also, it was assumed that the inclusions have two different orientations (i.e., square and rhombus shape) correspond to the loading direction. The orientations of the non-metallic inclusion in the metallic matrix are schematically illustrated in Figure 1. According to experimental tensile tests, appropriate ultimate tensile, yield stress and elongation were defined to Abaqus software. Also, the value of Young's modulus and Poisson's ratio of the studied inclusion was supposed to be 600 GPa and 0.25, respectively [25]. According to the tensile test, it was assumed that Young's modulus and the Poisson's ratio for the studied steel are $200 \mathrm{GPa}, 0.27$, 
respectively. The type of the explicit meshes which are selected for metallic matrix and non-metallic inclusion are C3D8R and R3D4, respectively [26]. By regarding the mentioned assumptions, stress field distribution at the interface of metallic matrix and non-metallic inclusion was simulated during plastic deformation.

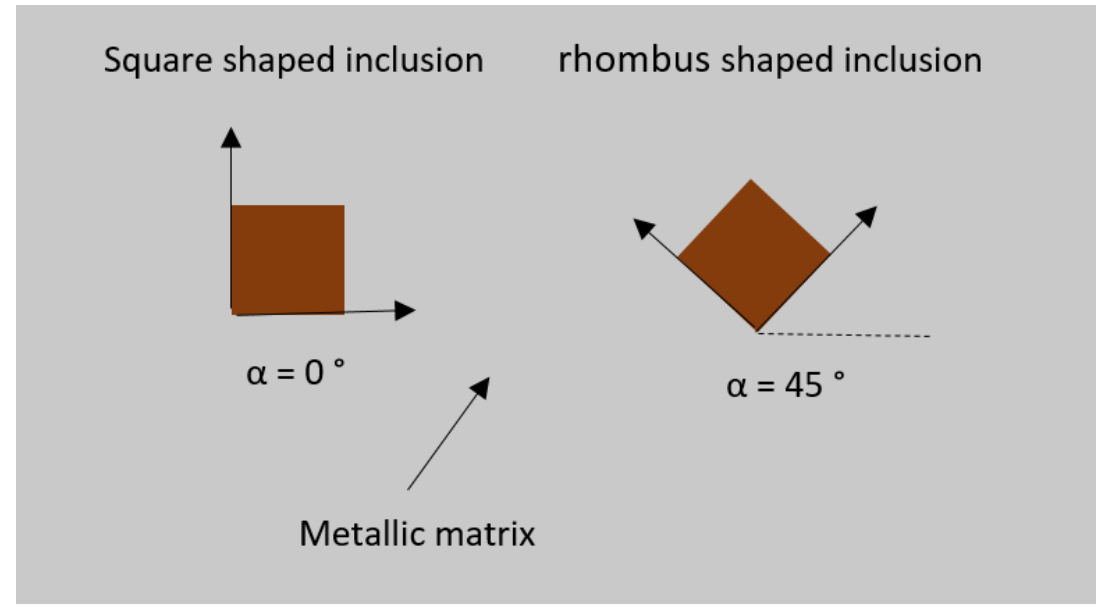

Fig. 1. A schematic presentation of the square and rhombus-shaped inclusion orientation in the metallic matrix.

\section{Result and Discussion}

The microstructure of titanium stabilized Fe-20Cr-9Ni steel is presented in Figure 2. It was clearly observed that the content of the inclusions in steel is noticeably reduced due to the electro-slag remelting process. According to Clemex analysis, the average size of inclusions is decreased from $50 \mu \mathrm{m}$ (Figure 2.a) to $5 \mu \mathrm{m}$ (Figure 2.b) as a result of the ESR process. In addition to reducing the size of the non-metallic inclusions, the number of inclusions is significantly decreased and homogenous microstructure is promoted. 

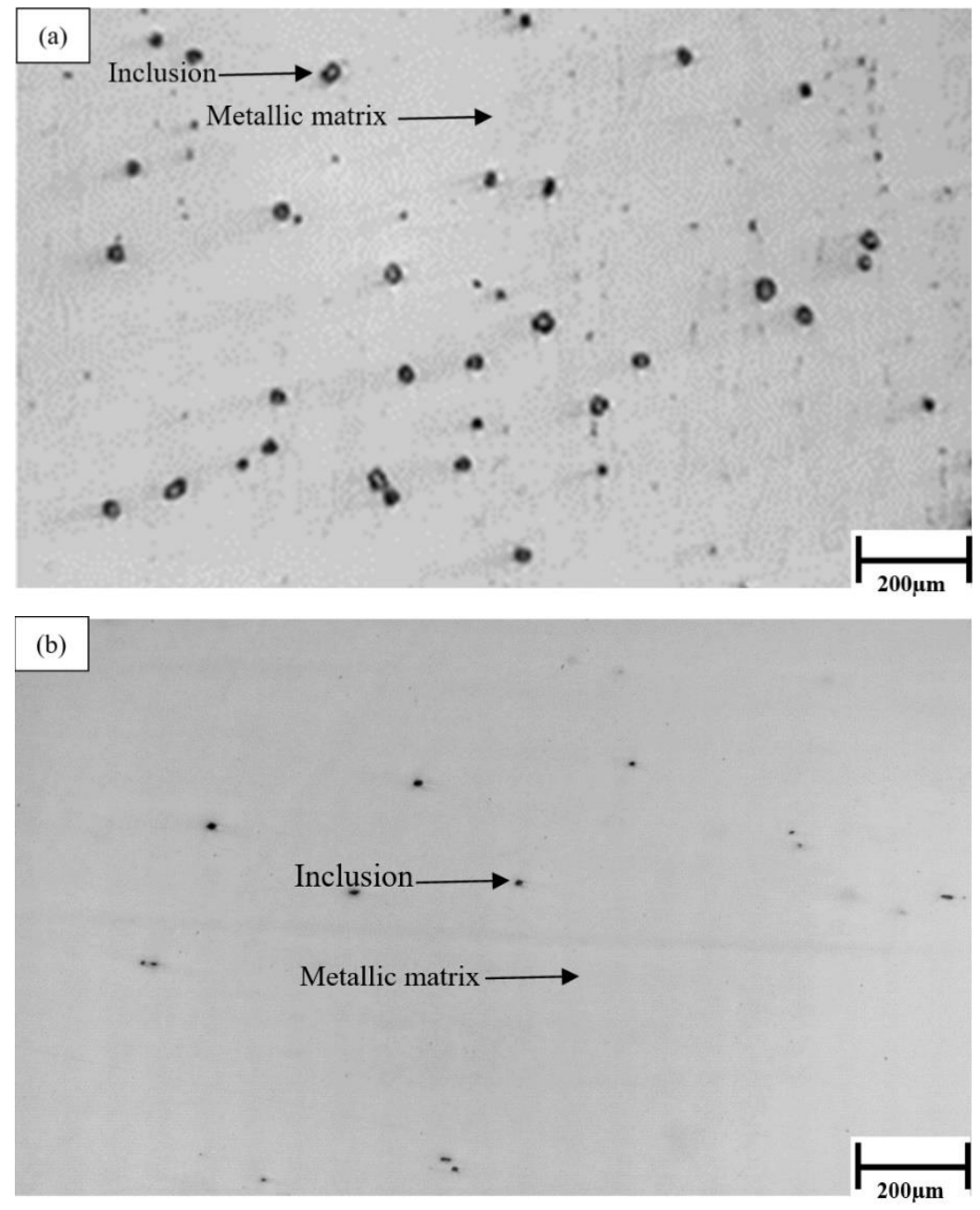

Fig. 2. The optical microstructure of the titanium stabilized Fe-20Cr-9Ni steel in as polished condition: (a) before the ESR process, (b) after the ESR process. 
SEM topographic image revealed that most of the non-metallic inclusions are square-shaped (Figure 3).

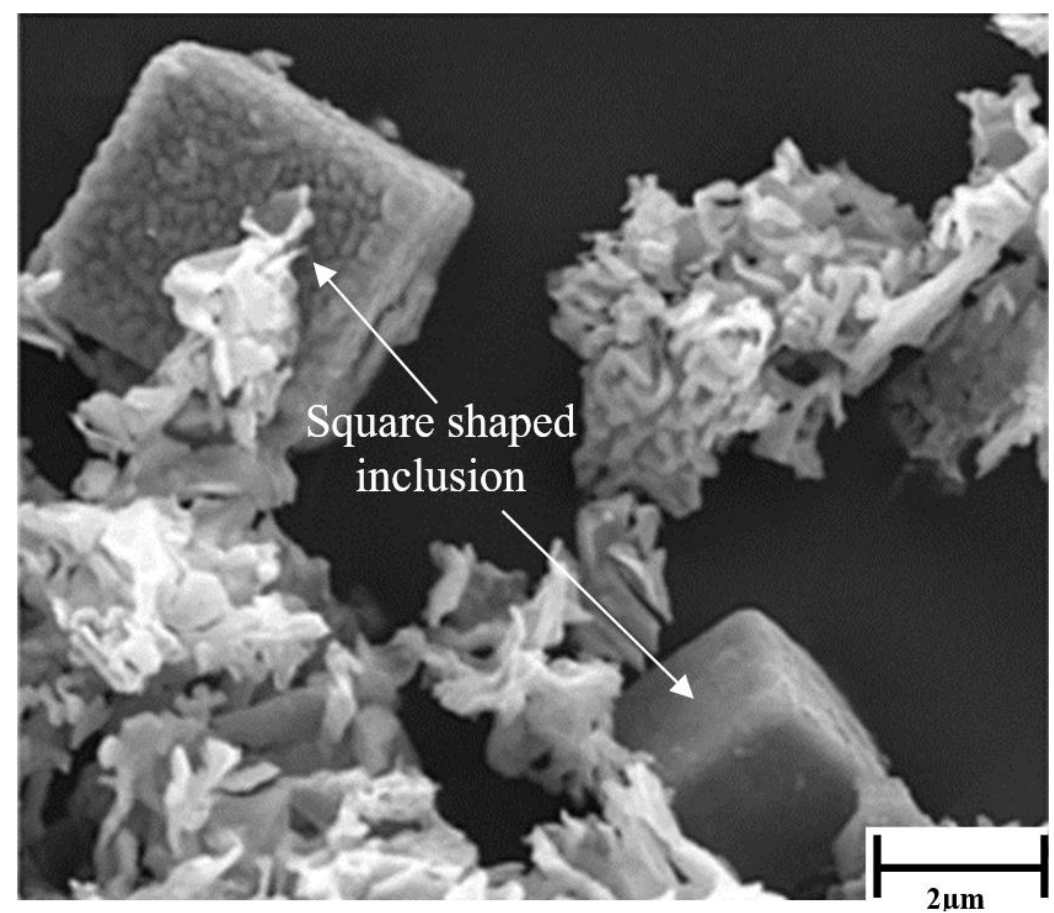

Fig. 3. The SEM topographic image of external TiN inclusion in titanium stabilized Fe-20Cr-9Ni steel after the ESR process.

It was previously observed that the morphology of nitride, oxide and sulfide inclusion which is appeared in steels, is square, globular, and elongated, respectively [8, $19,27]$. Therefore, it seems that most of the non-metallic inclusions, which are formed in the titanium stabilized Fe-20Cr-9Ni steel, are nitride type. This declaration is confirmed by energy dispersive spectroscopy (EDS). For this purpose, The EDS map of individual $\mathrm{Ti}, \mathrm{N}, \mathrm{Ni}$ and $\mathrm{Cr}$ was extracted in Figure 4. According to the EDS result, the concentration of Ti and $\mathrm{N}$ was obviously observed inside non-metallic inclusion. Also, NMI is deficient of $\mathrm{Cr}$ element and $\mathrm{Ni}$ was homogenously distributed through the matrix and non-metallic inclusion. 


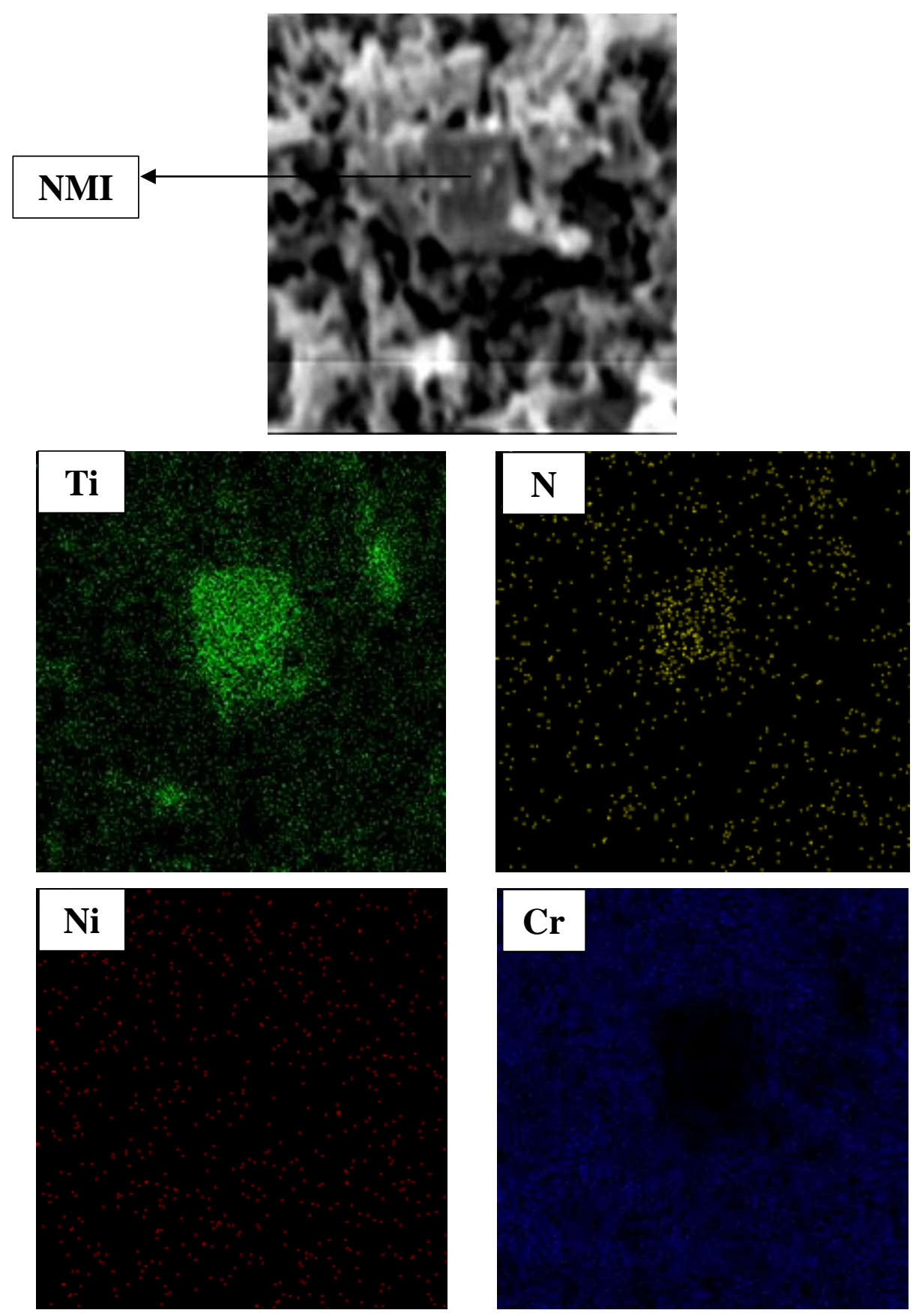

Fig. 4. The EDS map of distributed Ti, N, Ni, and Cr elements inside non-metallic inclusion. 
So, it can be certainly demonstrated that the nature of square-shaped inclusions which is appeared in titanium stabilized $\mathrm{Fe}-20 \mathrm{Cr}-9 \mathrm{Ni}$ steel is titanium nitride (TiN) type. In the following, the size and the type of non-metallic inclusion were determined according to the JK-inclusion rating method. The results of the JK-inclusion rating method are reported in Table 2 before and after the ESR process, respectively. The results revealed that most of the inclusions are D-type. Therefore, they are referred to as a squarelike and nitride inclusion. Their size is significantly decreased as a result of the ESR process which is compatible with the image analysis result (Figure 1).

Table 2. Determination of inclusions type and size according to the JK inclusion rating method.

\begin{tabular}{lll}
\hline \multirow{2}{*}{ Sample } & \multicolumn{2}{l}{ Oxide/ nitride inclusion (D type) } \\
\cline { 2 - 3 } & JK-thin series & JK-thick series \\
\hline Before ESR & 1.5 & 3 \\
\hline After ESR & $<1$ & $<1$ \\
\hline
\end{tabular}

The effect of the ESR process on tensile properties of $\mathrm{Fe}-20 \mathrm{Cr}-9 \mathrm{Ni}$ is reported in Table 3. The result indicated that the ESR process has a noticeable influence on ultimate tensile, yield stress and elongation of the studied steel. As a result of the ESR process, the value of ultimate tensile strength and yield stress has been increased by $17 \%$ and $25 \%$, respectively. Also, the value of elongation is approximately increased by 3.6 times.

Table 3. Tensile properties of Fe-20Cr-9Ni steel at room temperature.

\begin{tabular}{llll}
\hline Sample & UTS $(\mathrm{MPa})$ & YS $(\mathrm{MPa})$ & Elongation $(\%)$ \\
\hline Before ESR & 665 & 432 & 12 \\
\hline After ESR & 750 & 537 & 43 \\
\hline
\end{tabular}

Therefore, it can be demonstrated that excellent improvement in tensile properties occurs as a result of the ESR process. By decreasing inclusion size via the ESR process, the value of the concentrated stress at the interface of metallic matrix and non-metallic inclusion is declined therefore a remarkable improvement in tensile properties of the titanium stabilized Fe-20Cr9Ni steel is expected. Therefore, it can be demonstrated that the size of the deformed zone near non-metallic inclusions is an important criterion for failure analysis. The deformed zone near non-metallic inclusion is directly related to inclusion size, morphology and orientation through-loading direction. The effect of inclusion size $(d=5,10,25,50 \mu \mathrm{m})$ and its orientation $\left(\alpha=0,45^{\circ}\right)$ on stress distribution near the vicinity of inclusion are simulated in Figures 5-8. In the following, the minimum $\left(\sigma_{\min }\right)$ and maximum $\left(\sigma_{\max }\right)$ value of the Mises stress at the single inclusion and its adjacent vicinity was estimated. The stress concentration factor $(\mathrm{K})$ for each inclusion was calculated using eq. 1 :

$$
K=\frac{\left(\sigma_{\max }-\sigma_{\min }\right)_{\text {inclusion }}}{\left(\sigma_{\max }-\sigma_{\text {min }}\right)_{\text {matrix }}}
$$




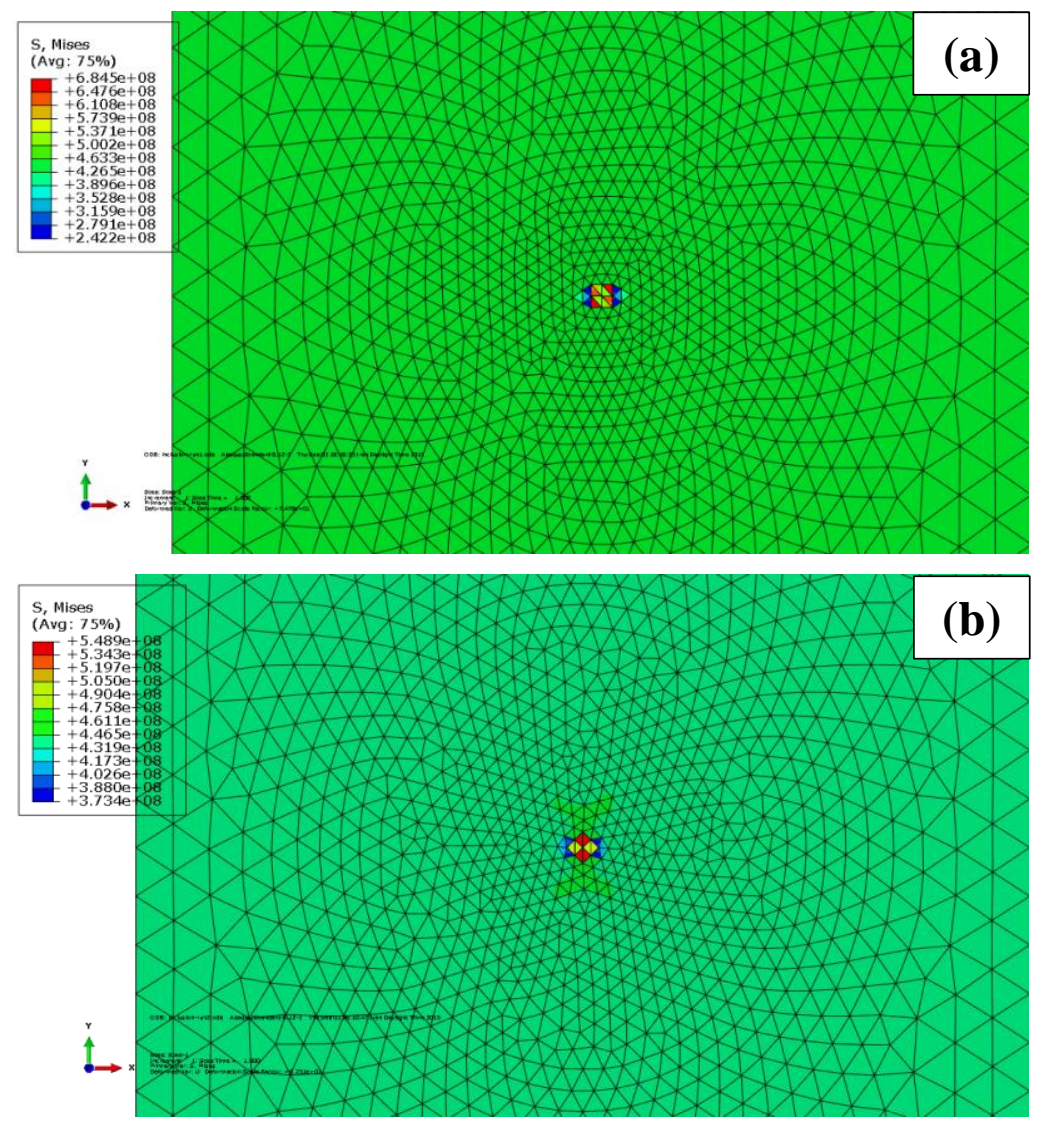

Fig. 5. The stress concentration contour at the interface of metallic matrix and nonmetallic inclusion during tensile loading of the titanium stabilized Fe-20Cr-9Ni steel, inclusion size $=5 \mu \mathrm{m}$ : (a) square-shaped, (b) rhombus-shaped.

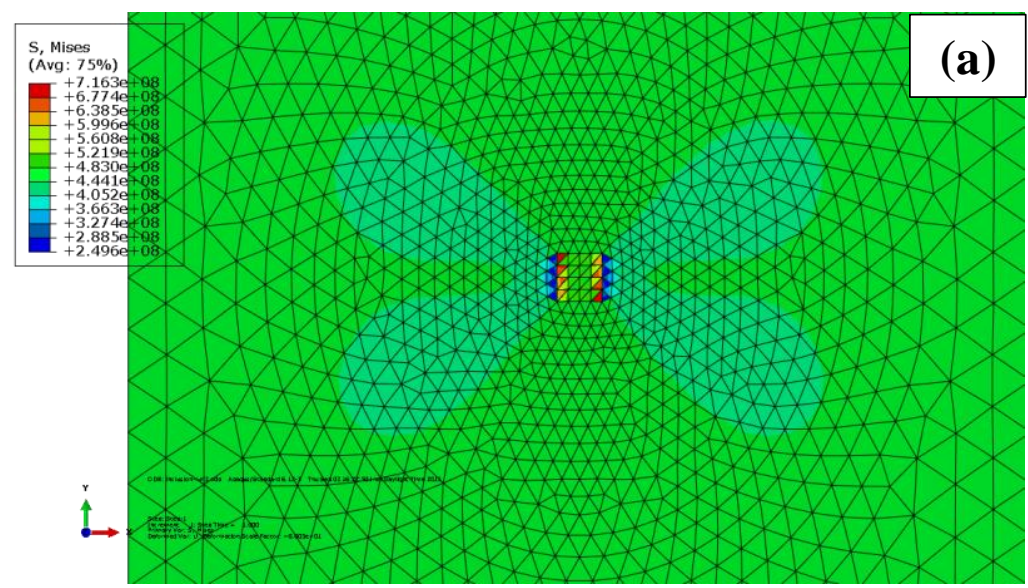




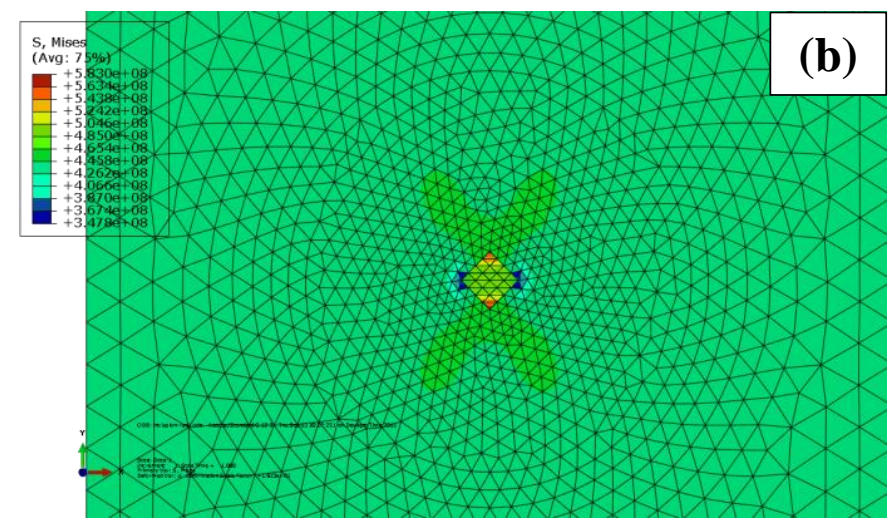

Fig. 6. The stress concentration contour at the interface of metallic matrix and nonmetallic inclusion during tensile loading of the titanium stabilized Fe-20Cr-9Ni steel, inclusion size $=10 \mu \mathrm{m}$ : (a) square-shaped, (b) rhombus-shaped.
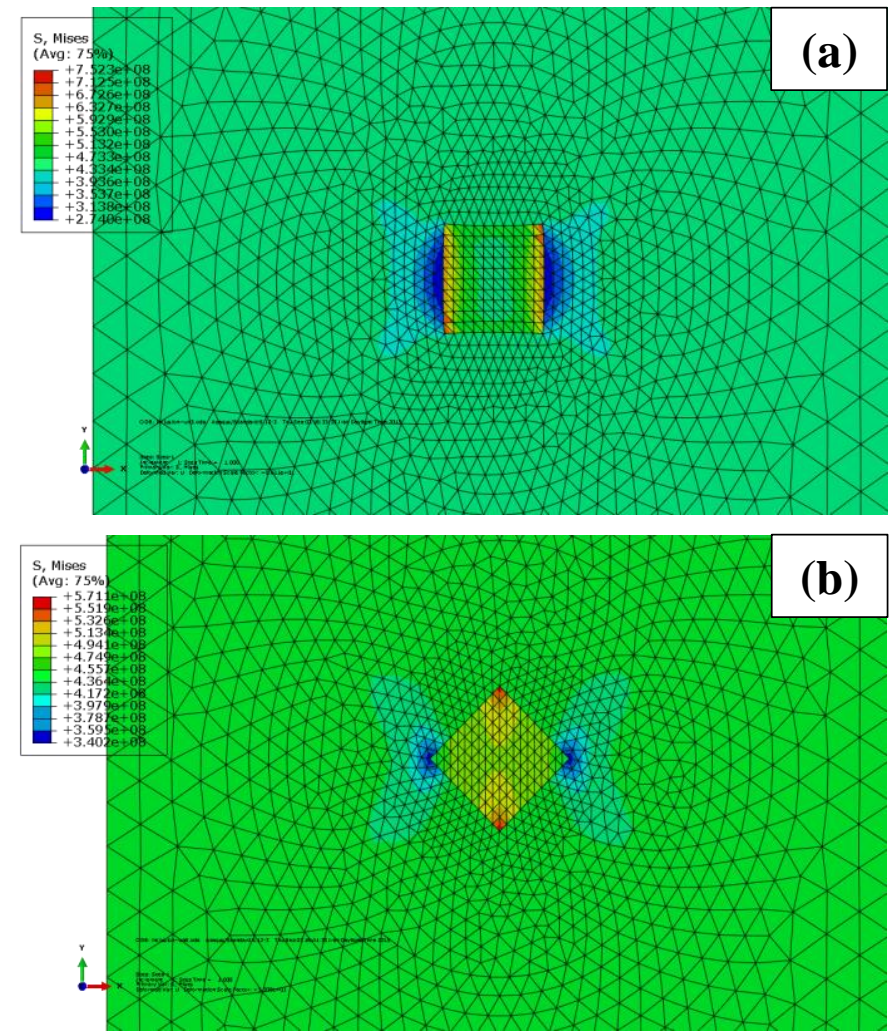

Fig. 7. The stress concentration contour at the interface of metallic matrix and nonmetallic inclusion during tensile loading of the titanium stabilized Fe-20Cr-9Ni steel, inclusion size $=25 \mu \mathrm{m}$ : (a) square-shaped, (b) rhombus-shaped. 


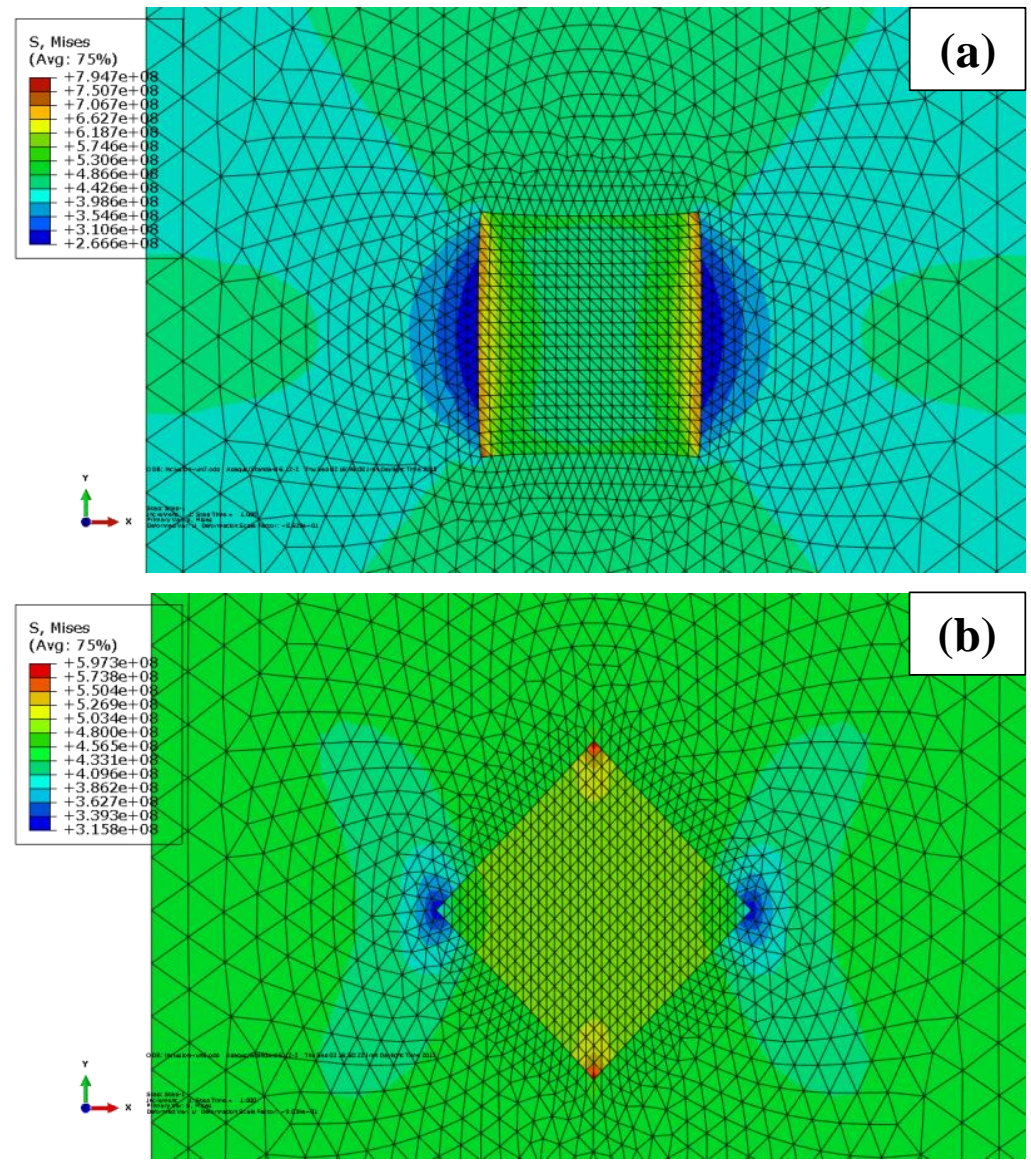

Fig. 8. The stress concentration contour at the interface of metallic matrix and nonmetallic inclusion during tensile loading of the titanium stabilized Fe-20Cr-9Ni steel, inclusion size $=50 \mu \mathrm{m}$ : (a) square-shaped, (b) rhombus-shaped.

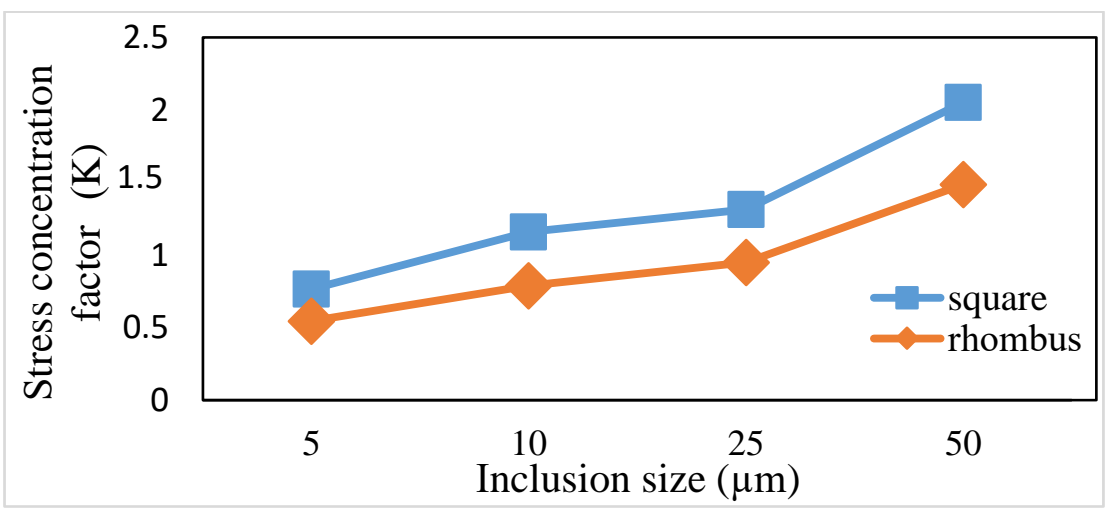

Fig. 9. the effect of inclusion size and its orientation on stress concentration factor $(K)$. 
In Figure 9, the effect of inclusion size and its orientation on the stress concentration factor is presented. For both square and rhombus inclusions, increasing inclusion size is associated with the high value of the stress concentration, which is deleterious for the mechanical response of the studied steel. In addition to the inclusion size effect on the stress concentration factor, it can be demonstrated that for the same inclusion size, rhombus inclusions show a high tendency for homogenous deformation in comparison with square one.

\section{Conclusion}

In this study, the effect of non-metallic inclusions on tensile properties of the titanium stabilized $\mathrm{Fe}-20 \mathrm{Cr}-9 \mathrm{Ni}$ steel has been investigated. For this purpose, the inclusion was characterized using the JK-inclusion rating method. Also, the chemical composition of the inclusion was determined by energy dispersive spectroscopy analysis. The result indicates that the electro-slag process has a significant influence on the size, number and distribution of the inclusions. The mechanical properties of the studied steel considerably improved as a result of the ESR process. According to the Abaqus result, it was revealed that stress concentration at the interface of metallic matrix and non-metallic inclusion is reduced by decreasing in TiN size. Also, rhombus-shaped inclusion shows a great tendency for homogenous deformation in comparison with a square-shaped one. Therefore, the nucleation and the propagation of cracks will retard due to small TiN inclusions which are appeared by the ESR process.

\section{Reference}

[1] D. Llewellyn, R. Hudd, Steels: Metallurgy And Applications, Elsevier, USA, 1998.

[2] V.S. Hristov, K. Yoshida: Procedia Manuf, 15, 341 (2018).

[3] J.I. Barraza-Fierro, B. Campillo-Illanes, X. Li, H. Castaneda: Metall Mater Trans A, 45 (2014) 3981.

[4] S. Sun, A. Zhao: Mater Sci Technol, 34, (2018) 347.

[5] M. Beltran-Zuñiga, J. González-Velázquez, D. Rivas-López, H. DorantesRosales, F. Hernández-Santiago: Fatigue Fract Eng M, 41 (2018) 749.

[6] Z. Cui, G.-h. Zhu, W.-m. MAO: J Iron Steel Res Int, 20 (2013) 66.

[7] B.R. Kumar: J Mater Sci, 45 (2010) 2598.

[8] A.L. Vasconcellos da Costa e Silva: J Mater Res Technol, 8 (2019) 2408

[9] C.-b. Shi, X.-c. Chen, H.-j. Guo: Metall Mater Trans B, 19 (2012) 295.

[10] R. Arreola-Herrera, A. Cruz-Ramírez, J.E. Rivera-Salinas, J.A. Romero-Serrano, R.G. Sánchez-Alvarado: Theor Appl Fract Mec, 94 (2018) 134.

[11] S. Henschel, S. Dudczig, L. Krüger, C. Aneziris: Procedia Structural Integrity 2 (2016) 358.

[12] I. Dugic, R. Berndt, S. Josefsson, M. Hedström, Non-metallic Inclusion and Their Effect on Fatigue Strength for Case-Hardened Carbon Steel in Gears TMS Annual Meeting \& Exhibition, Springer, USA, 2018.

[13] J. Guan, L. Wang, C. Zhang, X. Ma: Tribol Int, 106 (2017) 123.

[14] D. Krewerth, T. Lippmann, A. Weidner, H. Biermann: Int J Fatigue, 84 (2016) 40.

[15] N. Ånmark, A. Karasev, P. Jönsson: Materials, 8 (2015) 751.

[16] A.C. e Silva: Rare Metals, 25 (2006) 412.

[17] A. Pribulová, P. Futaš, M. Bartošová: Key Eng Mater, 635 (2015) 112. 
[18] S.-j. Li, G.-g. Cheng, Z.-q. Miao, L. Chen, X.-y. Jiang: Int J Min Met Mater, 26 (2019) 291.

[19] J. Burja, F. Tehovnik, M. Godec, J. Medved, B. Podgornik, R. Barbič: J Min Metall B. 54, 51 (2018).

[20] S. Ahmadi, H. Arabi, A. Shokuhfar, A. Rezaei: J Mater Sci Technol 25, 592 (2009)

[21] A. Pribulová, P. Futáš, A. Kmita, D. Márasová, M. Holtzer: Arch Metall Mater, 62 (2017) 181.

[22] L. Zhen, C.-j. Liu, S. Qun, M.-f. Jiang: J Iron Steel Res Int International, 22 (2015) 104.

[23] Y. Chen, X. Dai, X. Chen, B. Yang: Mater Charact, 149 (2019) 74.

[24] S. Jones, K. Williams, Titanium-Stabilized Stainless Steels as Alternative Partial Denture Casting Alloys Proceedings of the First International Conference on Interfaces in Medicine and Mechanics, Dordrecht, Netherland, 1989, pp. 342-358.

[25] E. Bailey, N.M. Ray, A.L. Hector, P. Crozier, W.T. Petuskey, P.F. McMillan: Materials, 4 (2011) 1747.

[26] Hibbitt, Karlsson, Sorensen: ABAQUS/Explicit: user's manual, Hibbitt, Karlsson and Sorenson Incorporated, USA, 1998.

[27] G. Jeanmaire, M. Dehmas, A. Redjaïmia, S. Puech, G. Fribourg: Mater Charact, 98 (2014) 193.

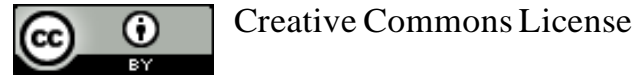

This work is licensed under a Creative Commons Attribution 4.0 International License. 